\title{
O MODAL CICLOVIÁRIO NA CIDADE DE PATO BRANCO - PR: Análise do atual sistema cicloviário e das vias do anel central
}

\author{
Rayana Carolina Conterno \\ Universidade Tecnológica Federal do Paraná \\ Orientadora da pesquisa \\ rayana_arq@hotmail.com \\ Jairo Trombetta \\ Universidade Tecnológica Federal do Paraná \\ Co-orientador da pesquisa \\ jairotrombetta@utfpr.edu.br

\section{Thiago Augusto Ruaro} \\ Universidade Tecnológica Federal do Paraná \\ Autor da pesquisa \\ thiago.ruaro@gmail.com
}

\section{RESUMO}

Visando o desenvolvimento sustentável das cidades, este trabalho tem por objetivo avaliar a infraestrutura cicloviária existente na cidade de Pato Branco - PR, bem como, analisar uma área delimitada dentro da região central da cidade com foco na implantação de uma rota cicloviária. Para a avaliação da infraestrutura cicloviária existente, utilizou-se de forma parcial a ferramenta IMUS - Índice de Mobilidade Urbana Sustentável. Já para a análise das vias, fez-se uso das ferramentas: Nível de Stress de Sorton e Walsh e Índice de Condição das Vias (ICV) de Epperson-Davis. Cruzando os resultados obtidos pelas ferramentas e a avaliação subjetiva realizada em campo, apresentou-se a classificação final das vias em um mapa síntese. Concluiu-se, a respeito do sistema cicloviário atual, que este não está sendo pensado de forma integrada. Em relação à área delimitada na região central, verificou-se que a maior parte das vias possui grande potencial em comportar rotas cicloviárias.

Palavras-chave: Sistema cicloviário. Mobilidade Urbana. Ferramentas.

\begin{abstract}
Aiming at the sustainable development of cities, this study aims to evaluate the existing bicycle infrastructure in the city of Pato Branco - PR, as well as to analyze a delimited area within the central region of the city focusing on the implementation of a cycleway route. For the evaluation of the existing bicycle infrastructure, the IMUS - Urban Sustainable Mobility Index tool was used in a partial way. For the analysis of the routes, the following tools were used: Sorton and Walsh Stress Level and Epperson-Davis Road Conditions Index (ICV). Crossing the results obtained by the tools and the subjective evaluation performed in the field, the final classification of the pathways was presented in a synthesis map. It was concluded, regarding the current cycle system, that this is not being thought in an integrated way. In relation to the area delimited in the central region, it was verified that most of the roads have great potential in behaving cycleway routes.
\end{abstract}

Key words: Cycle system. Urban mobility. Tools. 


\section{INTRODUÇÃO}

Com a industrialização ocorrida no Brasil na metade do século XX, ocorreu um forte impulso do êxodo rural no país e as cidades cresceram de forma acelerada e desordenada ocasionando diversos efeitos sociais, econômicos e ambientais no espaço físico dos centros urbanos (Brasil, 2007). Projetos e planejamento de infraestrutura foram sendo estrangulados com essa nova realidade urbana. No Brasil, a urbanização desordenada trouxe consigo a ampliação das carências sociais e dos serviços públicos, degradação ambiental e o sufocamento da infraestrutura nas cidades, principalmente nos setores de saneamento, habitação e transporte (Rolnik, 2004).

Quando se discute as questões relacionadas aos sistemas de transporte, pode-se destacar que suas principais dificuldades estão relacionadas à acessibilidade e mobilidade urbana, pois devido à setorização do meio urbano e mal planejamento dos sistemas de transporte - causando conflitos ao invés de integração entre modais - são gerados congestionamentos, acidentes, eliminação de parte de áreas verdes para ampliação de espaços de circulação e estacionamentos de veículos comprometendo a qualidade ambiental, e por consequência, a vida da população (Conterno, 2013).

Contudo, a Política Nacional de Mobilidade Urbana, traz novas expectativas ao desenvolvimento, exigindo que os municípios elaborem e apresentem um Plano de Mobilidade Urbana visando o planejamento e crescimento de forma ordenada. Esta lei (12.597/2012) estabelece que nestes planos sejam priorizados o modo de transporte não motorizado e os serviços de transporte público coletivo (Brasil, 2012).

No município de Pato Branco, Paraná, diante de seu crescimento populacional e da sua elevada frota de veículos automotores, retratando o quadro apresentado anteriormente, tanto nas características de crescimento desordenado, quanto nos problemas de mobilidade. O município apresenta uma frota média por habitante maior que a do estado e do país, sendo que 38 a cada 100 habitantes possuem automóvel, apesar da média no estado ser de 34 automóveis, e no Brasil de 21, para cada 100 pessoas (Logitrans, 2015).

Para piorar ainda mais a situação na cidade, a infraestrutura cicloviária, raramente existente, é precária, bem como a frota do transporte público coletivo e sua infraestrutura de auxílio é insuficiente. Somado a isto, existe na cultura da população a necessidade de utilizar o transporte individual motorizado para realizar seus deslocamentos, sejam estes para locais próximos ou distantes ao ponto de partida.

Portanto, tendo em vista as problemáticas de Pato Branco, bem como a falta de infraestrutura cicloviária, somada à necessidade de um modo de transporte alternativo para controlar o crescente aumento de tráfego de veículos motorizados, esta pesquisa tem o objetivo de analisar a qualidade das vias da região central a partir da perspectiva do modal cicloviário, visto que a bicicleta tem se mostrado uma das melhores alternativas para deslocamentos de curta e média distância, pois além da agilidade, este modal contribui para a diminuição da poluição e aumento da qualidade de vida.

De forma mais detalhada, este trabalho consiste em um breve levantamento do sistema cicloviário existente na cidade, bem como, estudar as características das vias de uma zona de estudo delimitada da região central, visando a sugestão das vias que melhor se adequam para se tornarem rotas cicláveis e receberem infraestrutura para bicicletas.

\section{CARACTERIZAÇÃO DA CIDADE EM ESTUDO}

A cidade de Pato Branco (Figura 1) localiza-se na região sul do Brasil, Estado do Paraná. Juntamente com Palmas, Francisco Beltrão, Clevelândia e outros 38 municípios, constitui o sudoeste do Estado do Paraná. O município possui área total de aproximadamente $539,029 \mathrm{~km}^{2}$, sendo $54,04 \mathrm{~km}^{2}$ referente ao perímetro urbano (Conterno, 2013). De acordo do IBGE - Instituto Brasileiro de Geografia e Estatística - a população em 2010 alcançava 72.370 habitantes entre moradores da zona urbana e rural. A estimativa realizada pelo IBGE aproxima a população em 78.136 habitantes para 2014.

A região central da cidade é de uso misto e possui alta densidade demográfica, visto que é a área da cidade com maior quantidade de edificações verticais. Percebe-se, na cultura local, grande valorização ao automóvel pelo status em se possuir um carro, e também o entendimento de que a principal função das 
ruas é possibilitar o deslocamento através do modal individual motorizado e o estacionamento dos automóveis.

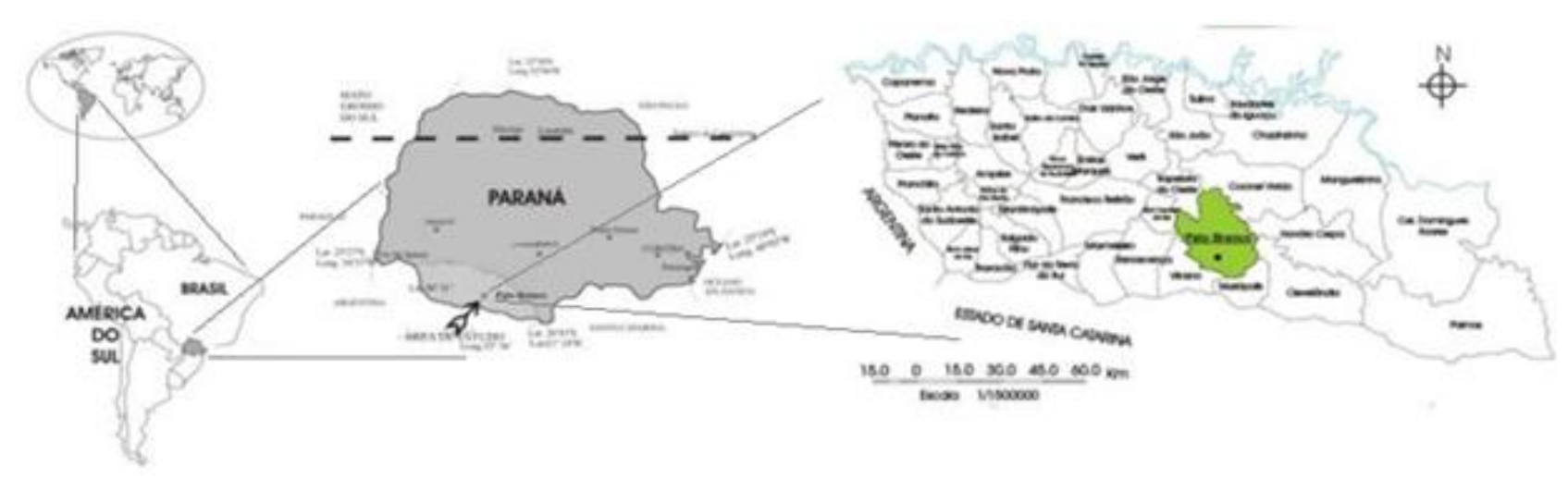

Figura 1: Localização do Município de Pato Branco

(Adaptado de Tabalipa, 2008).

Em relação ao uso do transporte coletivo, analisa-se que a maior parte das viagens cotidianas tem origem em bairros periféricos - com renda média mais baixa - com destino ao centro da cidade. As viagens que divergem significativamente deste contexto são as dos estudantes universitários que tem a origem de suas viagens na região central com destino às instituições de ensino superior na região norte (Logitrans, 2015). Logo, percebe-se que a área central concentra tanto os usuários do transporte coletivo que passam a ser pedestres e os usuários do transporte individual motorizado, que tendo achado uma vaga para estacionamento, tornam-se pedestres. Com isso, a sobrecarga do sistema ocorre nos horários do pico, quando todos tendem a deixar a área central ao mesmo tempo.

Como parte considerável das viagens de automóveis tem origem e destino na área central da cidade, estas viagens poderiam ser substituídas por viagens de bicicleta, aliviando o trânsito de veículos automotores. Além disso, havendo integração entre o transporte coletivo e o sistema cicloviário, os moradores de bairros periféricos poderiam utilizar a bicicleta desde a sua casa até o terminal de ônibus e tornar suas viagens mais ágeis.

Contudo, atualmente é praticamente inexistente uma infraestrutura cicloviária que proporcione conforto e segurança aos ciclistas na área central da cidade ou mesmo nos bairros próximos onde a topografia é propícia à utilização deste modal. Entretanto, o que existe são trechos de passeio compartilhado em áreas periféricas e uma ciclofaixa no bairro Fraron, que apesar do bom design, não é integrada a nenhuma rota cicloviária.

\section{METODOLOGIA}

\subsection{METODOLOGIA PARA ANÁLISE DO SISTEMA CICLOVIÁRIO EXISTENTE}

Com o objetivo de avaliar a qualidade da mobilidade urbana, em específico do sistema cicloviário da cidade de Pato Branco, realizou-se uma pesquisa sobre métodos reconhecidos e testados que pudessem servir como base teórica para esta avaliação. Dentre outros sistemas de coleta e processamento de indicadores, 0 que melhor se encaixou para este objeto de estudo foi o IMUS - Índice de Mobilidade Urbana Sustentável.

\subsubsection{IMUS - Índice de Mobilidade Urbana Sustentável}

A ferramenta IMUS, desenvolvida pela engenheira Marcela da Silva Costa em 2008, é uma ferramenta que visa gerar um índice avaliador da mobilidade urbana sustentável da cidade/região em que foi aplicada. A ferramenta é estruturada hierarquicamente de maneira a abranger os aspectos da sustentabilidade, levando em consideração aspectos de planejamento urbano, engenharia de tráfego, cidadania, políticas públicas, acessibilidade, meio-ambiente, entre outros.

Como o foco deste trabalho é o sistema cicloviário, apenas os indicadores diretamente relacionados com este modal foram adotados. Portanto, como a quantidade de indicadores analisados é muito pequena em 
comparação com a quantidade total, considera-se que a ferramenta foi utilizada de forma parcial e o seu sistema de avaliação específico não foi levado em consideração.

Os indicadores selecionados da ferramenta são os relacionados ao sistema cicloviário. Na hierarquia da IMUS, os indicadores selecionados relacionados ao sistema cicloviário são os observados na Figura 2.

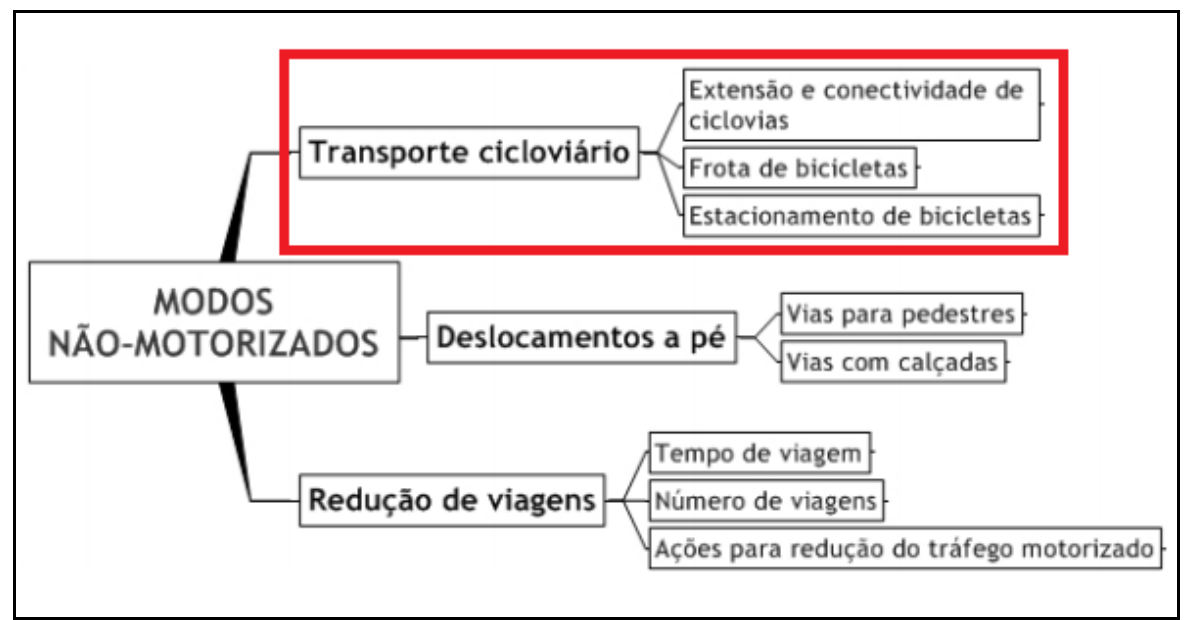

Figura 2: Detalhe do domínio Modos Não Motorizados (Adaptado de Costa, 2008)

Para cada indicador selecionado, o Quadro 1 apresenta em especial, as informações necessárias para sua avaliação e a fonte dos dados.

\begin{tabular}{|c|c|c|c|}
\hline INDICADOR & $\begin{array}{c}\text { EXTENSÃO E } \\
\text { CONECTIVIDADE DE } \\
\text { CICLOVIAS }\end{array}$ & $\begin{array}{l}\text { FROTA DE } \\
\text { BICICLETAS }\end{array}$ & ESTACIONAMENTO DE BICICLETAS \\
\hline DEFINIÇÃO & $\begin{array}{c}\text { Cobertura e conectividade } \\
\text { da rede de vias para } \\
\text { bicicleta. }\end{array}$ & $\begin{array}{c}\text { Número de bicicletas } \\
\text { por } 100 \text { habitantes no } \\
\text { município. }\end{array}$ & $\begin{array}{l}\text { Porcentagem dos terminais de transporte } \\
\text { público urbano que possuem } \\
\text { estacionamento para bicicletas. }\end{array}$ \\
\hline UNIDADE DE MEDIDA & $\begin{array}{l}\text { Porcentagem de vias (\%) } \\
\text { e Grau de conectividade }\end{array}$ & $\begin{array}{c}\text { Bicicletas } / 100 \\
\text { habitantes }\end{array}$ & Porcentagem dos terminais $(\%)$ \\
\hline CONTRIBUIÇÃOO & Maior/Melhor - (+) & Maior/Melhor - (+) & Maior/Melhor - (+) \\
\hline FONTES DE DADOS & DEPATRAN / IPPUPB & $\begin{array}{c}\text { IBGE / IPPUPB / } \\
\text { Comércios de bicicletas }\end{array}$ & DEPATRAN / IPPUPB \\
\hline MÉTODO DE CÁLCULO & Consultar Costa (2008) & Consultar Costa (2008) & Consultar Costa (2008) \\
\hline
\end{tabular}

Quadro 1: Indicadores adotados para avaliação do sistema cicloviário em Pato Branco - PR

(Adaptado de Costa, 2008)

Como esta aplicação da ferramenta foi parcial e nem todos os inputs foram passíveis de levantamento, os mesmos foram analisados e apresentados individualmente de forma descritiva, através da interpretação das informações adquiridas em campo.

Apesar de informações importantes terem sido levantadas, poucos dados numéricos foram obtidos, tendo somente um valor para a quantidade de pontos de ônibus com estacionamento para bicicletas. Já em relação à frota de bicicletas, os órgãos públicos não possuem nenhum tipo de registro e não foi possível conseguir as informações de bicicletas vendidas nos últimos sete anos junto às lojas de venda de bicicletas. Por fim, tratando-se da extensão e conectividade das ciclovias, a Prefeitura Municipal de Pato Branco não dispunha da informação do comprimento total da malha viária na área urbana, tampouco da malha cicloviária. Porém, foi possível levantar os trechos em que existem ciclovias ou ciclofaixas.

\subsection{METODOLOGIA PARA ANÁLISE DAS VIAS DO ANEL CENTRAL COM PERSPECTIVA NO MODAL CICLOVIÁRIO}

Além da análise da qualidade do sistema cicloviário existente na cidade de Pato Branco, almejou-se apresentar a qualidade das vias do anel central, para a partir disso, alternativas para rotas cicláveis possam ser pensadas de forma embasada.

\subsubsection{Definição da área de estudo}


Em virtude das características da região central da cidade (topografia, uso do solo, destino das viagens, etc.), definiu-se a área de estudo. A Figura 3 apresenta o espaço analisado (em vermelho), com as ruas e os cruzamentos delimitantes em destaque. Ao norte, a área é delimitada pelas ruas Osvaldo Aranha, Avenida Tupy e Itabira, a leste pelas ruas Itabira e Tocantins, a oeste pelas ruas Caramuru, Tamoio e Paraná e ao sul pelas ruas Mato Grosso e Itacolomi. Praticamente toda a área de estudo está no bairro Centro (em preto - mapa canto inferior esquerdo), exceto o extremo sul.

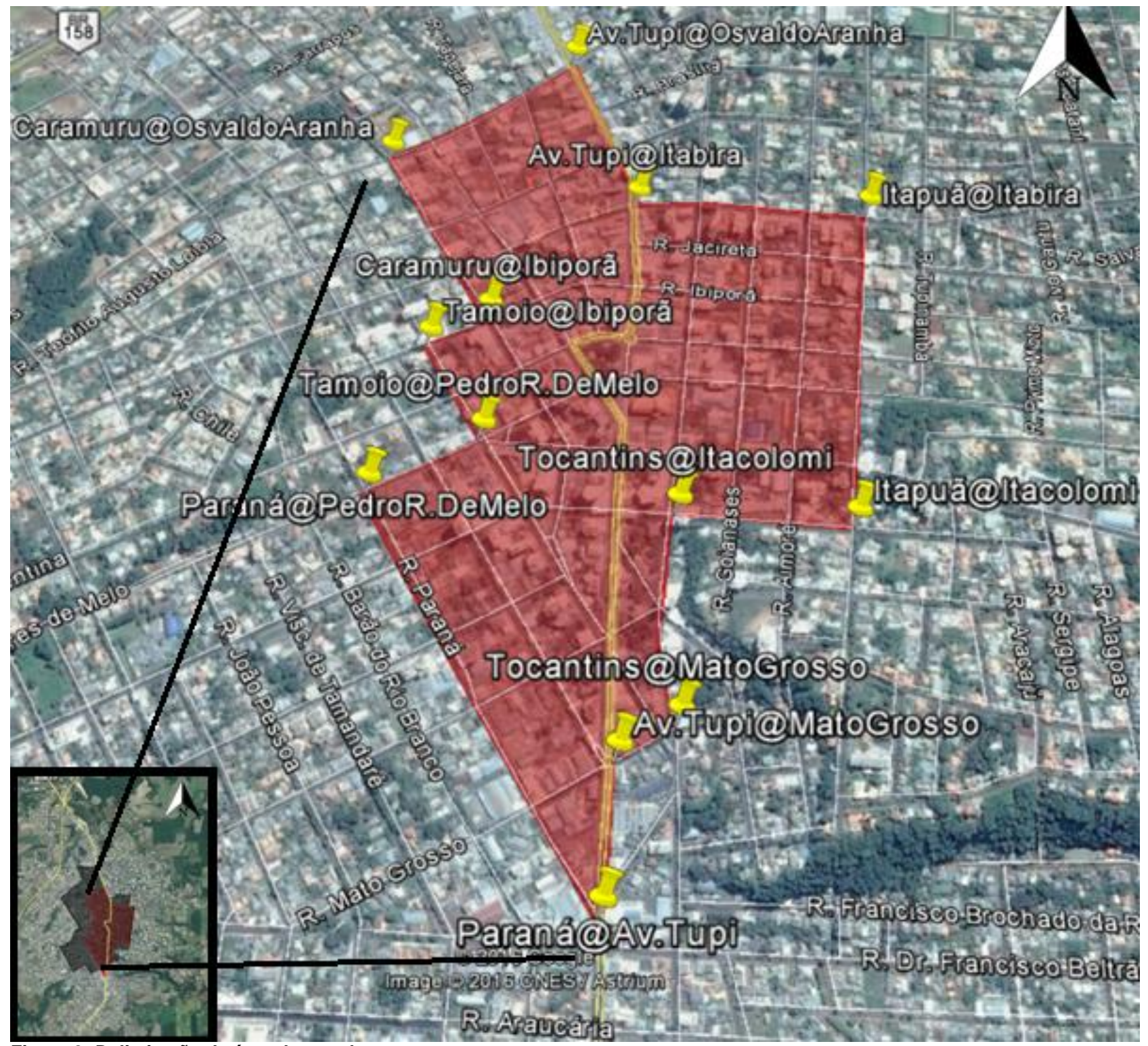

Figura 3: Delimitação da área de estudo

(Adaptado de Google Earth, 2016)

Como pode ser observado, a área de estudo é formada por cinquenta e sete quadras e abrange, de forma parcial, onze vias sentido Norte-Sul e treze vias sentido Leste-Oeste. Destaca-se que dez dessas vias são consideradas arteriais e outras duas são consideradas coletoras (Pato Branco, 2006).

Tratando-se de pontos de comércio e serviços, a área de estudo abrange três hospitais, dois colégios, quatro supermercados, igreja, teatro municipal e outros pontos de comércio e serviços. Além disso, esta é a região com maior número de edifícios verticais, o que gera uma alta densidade populacional.

Após uma rápida análise, verificou-se a heterogeneidade das vias, ou seja, uma mesma via apresenta características distintas no seu comprimento total. Desta forma, optou-se por dividi-las em trechos, considerando diferenças como declividade, sentido de tráfego, largura da faixa e demais condições físicas. 


\subsubsection{Método para estudo das vias}

O objetivo da análise das vias é facilitar uma futura proposta de traçado de rotas cicláveis que formem uma rede cicloviária dentro da área determinada para estudo. Então, para que fosse possível determinar quais ruas poderiam ser mais apropriadas, bem como quais os tipos de infraestrutura seriam necessários em cada trecho, fez-se necessário conhecer as características das vias. Assim, buscou-se na literatura metodologias que auxiliassem essa interpretação. Dentre os trabalhos levantados, dois adequaram-se aos objetivos deste estudo: (a) Nível de Stress de Sorton e Walsh (1994), e (b) Índice de Condição das Vias da Flórida - ICV Epperson-Davis (1994).

\section{a) Nível de Stress de Sorton e Walsh}

É bem conhecido o fato de que os ciclistas escolhem rotas que exigem menor esforço físico. Contudo, outro fator preponderante para esta escolha é a possibilidade de evitar o desconforto e a tensão de pedalar em ruas estreitas em meio a um grande volume de carros em alta velocidade. Portanto, destaca-se que os ciclistas querem minimizar não somente o esforço físico, mas também o esforço mental - stress (Sorton e Walsh, 1994).

Sorton e Walsh (1994) desenvolveram um método de avaliação do Nível de Stress a que o ciclista está submetido durante seu deslocamento, estabelecendo níveis de stress que variam de 1 a 5 (Quadro 2), e estão relacionados com volume de tráfego, velocidade e largura da via.

\begin{tabular}{|l|l|}
\hline NIVEL DE STRESS & \multicolumn{1}{c|}{ INTERPRETAÇÃo } \\
\hline $\mathbf{1}$ (Muito Baixo) & A via é razoavelmente segura para todos os tipos de ciclistas (exceto crianças com idade inferior a 10 anos) \\
\hline $\mathbf{2}$ (Baixo) & $\begin{array}{l}\text { A via pode acomodar ciclistas experientes e casuais e/ ou podem precisar de alterações ou ter condições } \\
\text { compensatórias de ajuste para acomodar ciclistas jovens. }\end{array}$ \\
\hline $\mathbf{3}$ (Moderado) & $\begin{array}{l}\text { A via pode acomodar ciclistas experientes e/ ou incluir condições compensatórias para acomodar ciclistas } \\
\text { casuais. Não é recomendada para ciclistas jovens. }\end{array}$ \\
\hline $\mathbf{4}$ (Alto) & $\begin{array}{l}\text { A via pode precisar de alterações e/ ou ter condições compensatória para acomodar ciclistas experientes. Não } \\
\text { é recomendada para ciclista casual ou jovem. }\end{array}$ \\
\hline $\mathbf{5}$ (Muito Alto) & A via pode não ser apropriada para uso de bicicleta. \\
\hline
\end{tabular}

Quadro 2: Níveis de Stress e Interpretações

(Adaptado de Sorton e Walsh, 1994)

O nível de stress é calculado através da média dos valores gerados a partir de três indicadores: volume de tráfego no horário de pico; velocidade de tráfego por faixa; e, largura da faixa externa.

- $\quad$ Volume de Tráfego X Nível de Stress:

Como existe uma grande oscilação do volume de veículos durante o dia, o volume diário médio (VMD) não é um bom indicador, portanto, o autor utiliza o volume no horário de pico (VHP), visto que como o VHP será mais alto que o VMD, o nível de stress fora do horário de pico será menor. Se for o caso da via ter mais de uma faixa de rolamento para determinada direção, será considerado o volume total dividido pelo número de faixas.

Analisando os pesos originais da ferramenta (Tabela 1) percebeu-se que da forma como é apresentada (com o volume em número absoluto ao invés de um intervalo) não seria possível realizar a classificação das vias, visto que haveria um hiato entre um nível e outro. Para isso, optou-se por adaptar os pesos classificando o Nível de Stress através de intervalos, porém, mantendo um intervalo que mantivesse um valor médio de grandeza semelhante ao original, bem como um intervalo semelhante para níveis intermediários.

\begin{tabular}{c|c|c}
\hline NIVEL DE STRESS & $\begin{array}{c}\text { VOLUME POR FAIXA (V/F/H) } \\
\text { Pesos originais }\end{array}$ & $\begin{array}{c}\text { VOLUME POR FAIXA (V/F/H) } \\
\text { Pesos adaptados }\end{array}$ \\
\hline $\mathbf{1}$ & $<50$ & $\mathrm{~V}<75$ \\
\hline $\mathbf{2}$ & 150 & $75 \leq \mathrm{V}<200$ \\
\hline $\mathbf{3}$ & 250 & $200 \leq \mathrm{V}<325$ \\
\hline $\mathbf{4}$ & 350 & $325 \leq \mathrm{V}<450$ \\
\hline $\mathbf{5}$ & $>450$ & $450 \leq \mathrm{V}$ \\
\hline
\end{tabular}

Tábela 1: Volume de Tráfego por Faixa X Níveis de Stress

(Adaptado de Sorton e Walsh, 1994). 
Os volumes de tráfego para os trechos em análise foram obtidos através de um estudo realizado em 2012, disponibilizado pelo DEPATRAN e contempla a contagem de tráfego de doze cruzamentos durante os seguintes intervalos de horário: $11 \mathrm{~h} 30$ às 14h30; e 17h00 às 19h00. Contudo, como este foi o único material disponibilizado pelos órgãos responsáveis da PMPB, e não haviam dados quanto ao fluxo de veículos em todas as faixas das vias, em alguns casos a análise referente ao Nível de Stress X Volume de Tráfego não pode ser realizada.

- Largura da Faixa Externa X Nível de Stress:

Considera-se a largura da faixa externa uma variável crítica, visto que delimita o espaço de circulação dos ciclistas. Havendo estacionamento na via, a largura da faixa externa deve ser medida a partir da faixa de estacionamento. Caso não exista estacionamento, a distância a ser considerada é a partir da guia lateral (faixa amarela).

De forma semelhante à Tabela 1, verificou-se a necessidade de adaptar os pesos da ferramenta de largura das faixas para intervalos para que fosse possível classificar o Nível de Stress das vias de maneira mais assertiva (Tabela 2).

\begin{tabular}{c|c|c}
\hline NÍVEL DE STRESS & $\begin{array}{c}\text { LARGURA DA FAIXA (M) } \\
\text { Pesos originais }\end{array}$ & $\begin{array}{c}\text { LARGURA DA FAIXA (M) } \\
\text { Pesos adaptados }\end{array}$ \\
\hline $\mathbf{1}$ & $>4,6$ & $4,3<\mathrm{L}$ \\
\hline $\mathbf{2}$ & 4,3 & $4,0<\mathrm{L} \leq 4,3$ \\
\hline $\mathbf{3}$ & 4 & $3,7<\mathrm{L} \leq 4,0$ \\
\hline $\mathbf{4}$ & 3,7 & $3,3<\mathrm{L} \leq 3,7$ \\
\hline $\mathbf{5}$ & 3,3 & $\mathrm{~L} \leq 3,3$ \\
\hline
\end{tabular}

Tabela 2: Largura da Faixa Externa X Níveis de Stress

(Adaptado de Sorton e Walsh, 1994)

As larguras das faixas nos trechos estudados foram obtidas in loco, onde com o uso de uma trena foi realizada a medição. Para o caso de vias com duas faixas no mesmo sentido, considerou-se sempre a faixa externa.

- Velocidade do Tráfego X Nível de Stress:

Como bicicletas e veículos trafegam lado a lado em uma faixa estreita, a velocidade dos automóveis tem impacto direto nos ciclistas, uma vez que geram movimentação de ar, barulho e distração.

Para a classificação das vias através da velocidade, observou-se a mesma limitação das tabelas anteriores. Portanto, foi necessário determinar intervalos de velocidade do tráfego, mas mantendo sempre os intervalos dentro da mesma ordem de grandeza dos valores originais (Tabela 3 ).

\begin{tabular}{c|c|c}
\hline NIVEL DE STRESS & $\begin{array}{c}\text { VELOCIDADE DO TRÁFEGO (KM/H) } \\
\text { Pesos originais }\end{array}$ & $\begin{array}{c}\text { VELOCIDADE DO TRÁFEGO (KM/H) } \\
\text { Pesos adaptados }\end{array}$ \\
\hline $\mathbf{1}$ & $\mathrm{v} \leq 40$ & $<40$ \\
\hline $\mathbf{2}$ & $40<\mathrm{v} \leq 50$ & 50 \\
\hline $\mathbf{3}$ & $50<\mathrm{v} \leq 60$ & 60 \\
\hline $\mathbf{5}$ & $60<\mathrm{v} \leq 70$ & 65 \\
\hline $\mathbf{y}$ & $70<\mathrm{v}$ & $>75$ \\
\hline
\end{tabular}

Tabela 3: Velocidade do Tráfego X Níveis de Stress

(Adaptado de Sorton e Walsh, 1994)

Em relação aos dados da velocidade do tráfego nas vias estudadas, estes não foram possíveis de serem obtidos, pois os órgãos responsáveis não possuíam nenhum estudo com estas informações. A informação disponível a respeito da velocidade nas vias é o limite de velocidade, que conforme informado pelo DEPATRAN, é de $40 \mathrm{~km} / \mathrm{h}$ em todas as vias dentro da área central. Contudo, como além de não ser o input necessário para esta análise do Nível de Stress, percebe-se que este limite não é respeitado em algumas vias estudadas. 


\section{b) Índice de Condição das Vias - ICV Epperson-Davis}

Em 1987, Davis desenvolveu um estudo com o objetivo de gerar um Índice de Segurança para Bicicletas. Segundo Epperson (1994), esta foi a primeira tentativa sistemática para desenvolver algum método de avaliação das condições operacionais de uma via para o uso da bicicleta, onde modificou alguns parâmetros do trabalho de Davis e aplicou para validação este novo método em Hollywood, Flórida, criando o Índice de Condição da Via - ICV Epperson-Davis. O objetivo do método é calcular este índice através da Equação 1, e posteriormente classificar a via conforme a Tabela 4.

\section{Equação 1: ICV $=\left[\mathrm{VMD} /\left(\mathrm{f}^{\star} 3100\right)\right]+(\mathrm{V} / 48)+\left\{(\mathrm{V} / 48)^{\star}\left[(\mathbf{4 , 2 5}-\mathrm{L})^{\star} 1,635\right]\right\}+\Sigma \mathrm{FP}+\Sigma \mathrm{FL}$}

Onde: $\mathrm{VMD}=$ Volume médio diário de tráfego (veículos $/$ hora); $\mathrm{f}=$ número de faixas de tráfego; $\mathrm{V}=$ limite de velocidade $(\mathrm{km} / \mathrm{h}) ; \mathrm{L}=$ largura da faixa externa (metros); $\mathrm{FP}=$ fator de pavimento; $\mathrm{e}, \mathrm{FL}=$ fator de localização.

\begin{tabular}{c|c}
\hline ICV & CLASSIFICAÇÃO \\
\hline 0 a 3 & Excelente \\
\hline 3 a 4 & Bom \\
\hline 4 a 5 & Regular \\
\hline$>5$ & Ruim \\
\hline
\end{tabular}

Tabela 4: Classificação da Via segundo ICV

(Adaptado de Epperson, 1994)

Para a obtenção dos valores de FP (fator de pavimento) e FL (fator de localização), deve-se analisar a Tabela 5 e a Tabela 6 respectivamente. Ressalta-se que a análise da tabela deve ser realizada com base em dados levantados em campo.

\begin{tabular}{|c|c|c|c|}
\hline FATOR & VALOR & FATOR & VALOR \\
\hline 1. Rachaduras & 0,5 & 5. Acostamento Irregular & \\
\hline 2. Remendos & \multirow{2}{*}{0,25} & \multirow{2}{*}{ 6. Cruzamento de ferrovia } & (dependendo da \\
\hline 3. Desgaste & & & \\
\hline 4. Buracos & $\begin{array}{c}0,25 \text { a } 0,50 \\
\text { (dependendo da } \\
\text { severidade) }\end{array}$ & 7. Bueiros & 0,5 \\
\hline
\end{tabular}

Tabela 5: Fatores de Pavimento

(Adaptado de Epperson, 1994)

\begin{tabular}{|c|c|c|c|}
\hline FATOR & VALOR & FATOR & VALOR \\
\hline \multicolumn{2}{|l|}{ 1. Movimento Transversal à Via } & \multicolumn{2}{|l|}{ 2. Alinhamento } \\
\hline a. Estacionamento em diagonal & 0,75 & a. Declividade acentuada & 0,50 \\
\hline b. Estacionamento em paralelo & 0,25 & b. Declividade moderada & 0,20 \\
\hline c. Faixa de conversão à direita (toda extensão) & 0,25 & c. Curvas horizontais frequentes & 0,35 \\
\hline d. Canteiro central (sem interrupção) & $-0,50$ & d. Distância de visibilidade reduzida & 0,50 \\
\hline \multirow{2}{*}{$\begin{array}{l}\text { e. Canteiro central (com baias para conversão à } \\
\text { esquerda) }\end{array}$} & \multirow{2}{*}{$-0,35$} & \multicolumn{2}{|l|}{ 3. Ambiente } \\
\hline & & a. Muitas entradas de garagem & 0,25 \\
\hline f. Faixa central para conversão (reversível) & $-0,20$ & b. Uso do solo predominantemente comercial & 0,25 \\
\hline g. Acostamento pavimentado ou ciclovia & 0,75 & c. Uso do solo predominantemente industrial & 0,25 \\
\hline
\end{tabular}

Tendo como referência a Equação 1, foram definidos os dados necessários para a obtenção do índice de Condição das Vias. Para a maioria deles, procedeu-se o levantamento de campo, porém a obtenção de 
algumas informações só ocorreu quando recorreu-se aos órgãos públicos. O Quadro 3 apresenta quais são estes dados e como foram obtidos.

\begin{tabular}{|c|c|c|}
\hline \multicolumn{2}{|c|}{ DADO } & OBTENÇÃo \\
\hline VMD & Vol. médio diário de tráfego (vei/hr) & $\begin{array}{c}\text { Plano de Modernização do Sistema de Circulação e Sinalização } \\
\text { Semafórica de Pato Branco (DEPATRAN) }\end{array}$ \\
\hline $\mathrm{f}$ & Número de faixas de tráfego & Levantamento de campo \\
\hline $\mathrm{V}$ & Limite de velocidade $(\mathrm{km} / \mathrm{h})$ & DEPATRAN \\
\hline $\mathrm{L}$ & Largura da faixa externa $(\mathrm{m})$ & Levantamento de campo \\
\hline $\mathrm{FP}$ & Fator de pavimento & Levantamento de campo \\
\hline $\mathrm{FL}$ & Fator de localização & Levantamento de campo \\
\hline
\end{tabular}

Quadro 3: Dados levantados para estudo do ICV

(2016)

Da mesma forma que para o Nível de Stress, a coleta do volume de tráfego utilizada foi a disponibilizada pela PMPB. Tais dados precisaram ser adaptados para sua utilização. Além de transformar estas informações de cruzamento para via, necessitou-se calcular o volume médio a partir dos dados iniciais.

Visando maior efetividade na coleta dos dados, estruturou-se uma planilha de coleta (Quadro 4). Nela constam todas as informações que podem ser obtidas no levantamento de campo, bem como identificação da rua e trecho em questão.

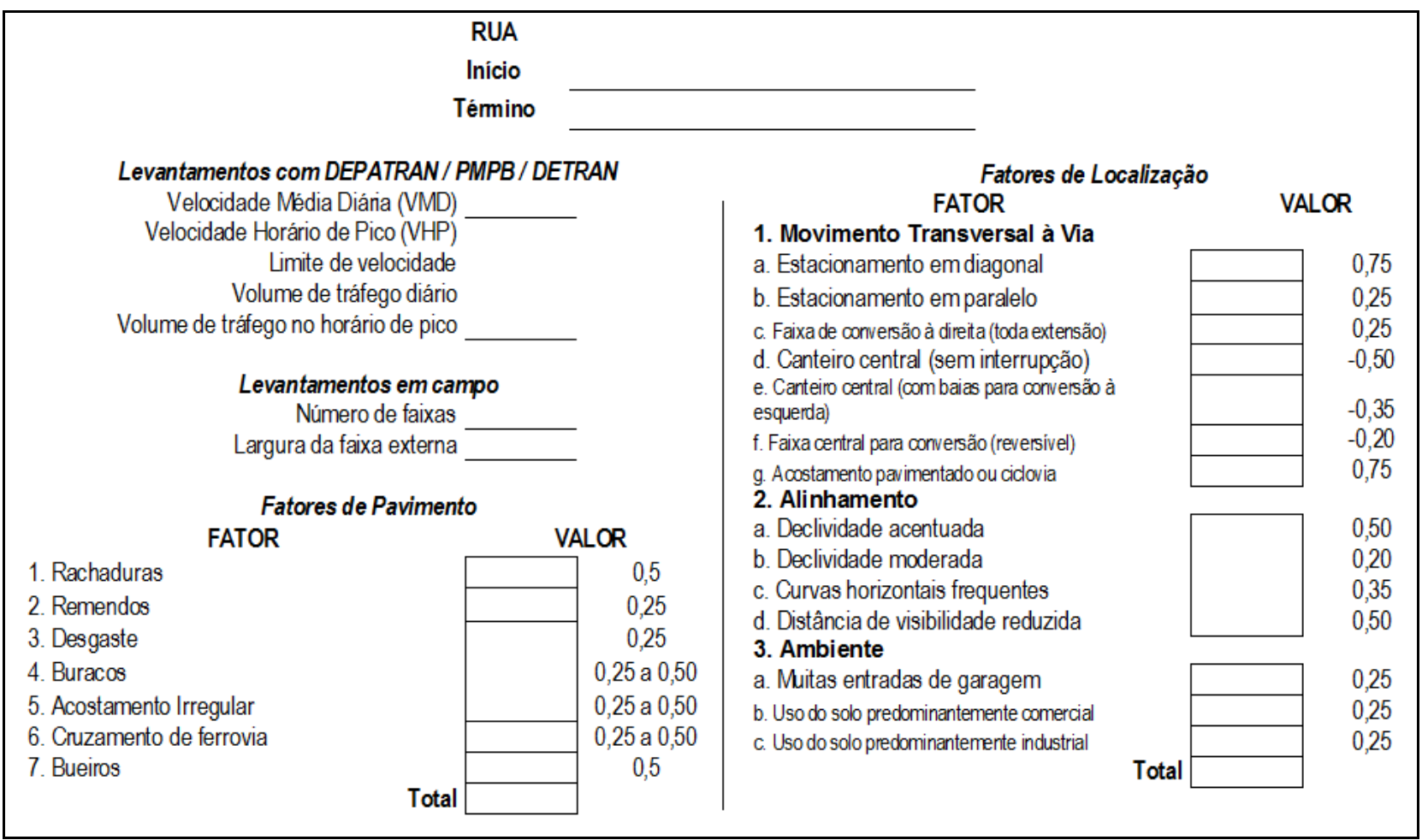

Quadro 4: Planilha para Levantamento de Campo

(2016)

\subsection{Avaliação dos Resultados}

Para obter maior compreensão sobre os resultados gerados através das ferramentas Nível de Stress e Índice de Condição das Vias, tendo em vista que cada uma classificou os trechos analisados dentro de suas particularidades e das limitações dos dados coletados, é fundamental uma avaliação descritiva em função da realidade que foi observada em campo.

Para facilitar a compreensão da classificação, optou-se por manter nomenclatura familiar ao que já vinha sendo apresentado nas classificações. Portanto, considerou-se quatro níveis de classificação das vias: Excelente, Bom, Regular, e Ruim. Para cada um desses níveis, atribuiu-se uma cor (Quadro 5). 


\begin{tabular}{|c|c|c|c|}
\hline CLASSIFICAÇÃO & COR CORRESPONDENTE & CLASSIFICAÇÃO & COR CORRESPONDENTE \\
\hline Excelente & & Regular & \\
\hline Bom & & Ruim & \\
\hline
\end{tabular}

Quadro 5: Classificação das vias

(2016)

Apesar da avaliação final dos resultados ser realizada de forma subjetiva, pois não é a partir de fórmulas ou intervalos de valores previamente expostos, destaca-se que se teve como base os valores e classificação dos autores referência para este trabalho. Contudo, para deixar mais clara a classificação aqui definida, descreve-se a seguir as características levadas em conta para cada nível:

- Excelente: Pouca interferência no layout da via. A via possui ruas largas de forma a poder acomodar ciclofaixas; Relevo plano, gerando pouco esforço físico para o ciclista; Velocidade e volume de tráfego moderados;

- Bom: Podem demander, ou não, alguma interferência no layout da via $\mathrm{A}$ via possui relevo com pouco declive, ruas largas com velocidade e tráfego moderado ou alto ou ruas mais estreitas, mas velocidade do tráfego baixa, de forma a possibilitar ciclofaixas ou compartilhamento de via;

- Regular: Necessidade de mudanças no layout da via A via possui relevo com pouco ou médio declive, já podendo demandar maior esforço físico, ruas estreitas que exijam compartilhamento da via, com moderado a alto volume de tráfego;

- Ruim: A via possui relevo muito inclinado, de maneira a exigir demasiado esforço físico do ciclista, e faixas estreitas que exijam compartilhamento da via.

\section{RESULTADOS E DISCUSSÕES}

Realizada a coleta de dados em campo e junto aos órgãos municipais descritos anteriormente, processaram-se os dados obtidos com o auxílio de planilhas no software Microsoft Excel e teve início a análise dos resultados gerados. Durante esse processamento e análise, percebeu-se, como já esperado, que não seria possível analisar as vias apenas através dos resultados diretos das ferramentas, mas sim que essas serviriam de base e auxílio para a interpretação, visto que alguns resultados das ferramentas não retratam a realidade percebida em campo.

\subsection{Análise do sistema cicloviário existente com base na ferramenta IMUS}

Como mencionado quanto a ferramenta IMUS, não foi possível obter dados como a frota de bicicletas do município, nem a extensão total da malha viária e cicloviária, para que fossem gerados os indicadores de porcentagem de cobertura da malha viária com rotas cicloviárias ou da porcentagem de bicicletas por habitantes. Contudo, estes indicadores serviram como direcionadores para embasar a busca de informações e a análise descritiva aqui realizada.

Para iniciar a análise, apresenta-se (Figura 3), um mapa da malha viária urbana do município de Pato Branco com a representação e indicação dos trechos onde há infraestrutura cicloviária, segundo a PMPB. 


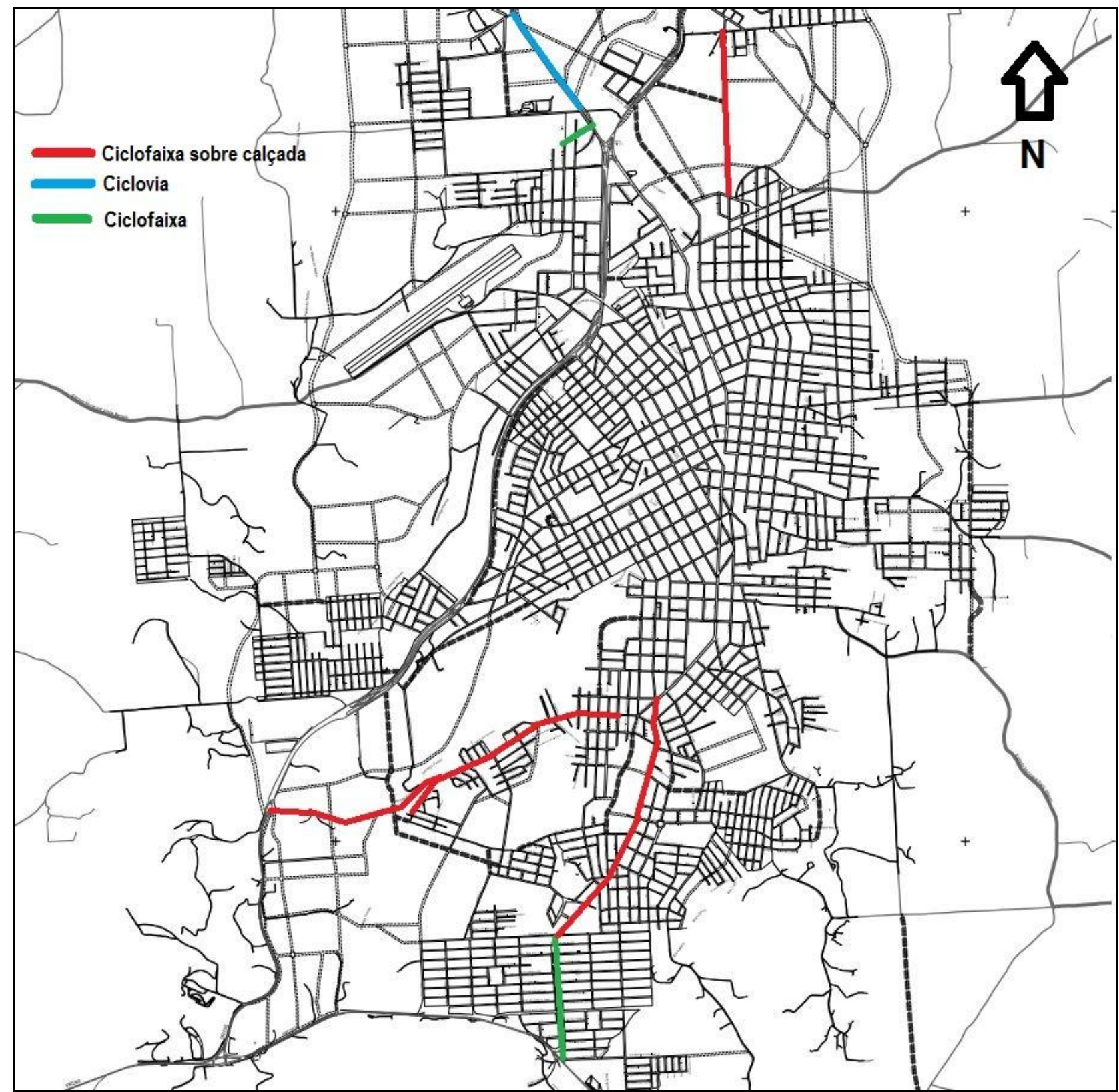

Figura 1: Malha cicloviária sobre malha viária urbana de Pato Branco

(Adaptado de Pato Branco, 2006)

Considerou-se três tipos de infraestrutura dos caminhos para os ciclistas: (a) ciclofaixa sobre calçada (em vermelho): caracteriza-se como uma faixa no mesmo nível da calçada, demarcada com pavers de cor diferente do utilizado na calçada, e sinalização horizontal e vertical; (b) ciclofaixa (em verde): caracteriza-se como uma faixa demarcada na lateral da caixa de rolamento, no mesmo nível das faixas dos veículos e em nível diferente da calçada. É demarcada com tinta e/ou tachões; e, (c) ciclovia (em azul): caracterizada por ser uma via separada fisicamente do tráfego de veículos e pedestres.

Como pode ser observado no mapa, na zona sul da cidade, existem duas vias com faixas para bicicleta, sendo elas a Rua Ivaí com ciclofaixa sobre calçada e a Avenida Tupy com ciclofaixa e ciclofaixa sobre calçada. Já na zona norte, observa-se a Rua Tocantins com ciclofaixa sobre calçada, a Via do Conhecimento (PR 493) com uma ciclovia e a Rua José Tato com duas quadras de ciclofaixa.

Percebe-se que não há conectividade entre as vias, nem entre as vias que estão próximas, muito menos uma rota cicloviária que conecte a cidade e possibilite o deslocamento do ciclista com segurança para uma via diferente da que esteja trafegando. Percebe-se ainda que na região central da cidade, onde há o maior fluxo de pessoas e veículos, não há nenhuma infraestrutura para a bicicleta. 
$\mathrm{Na}$ zona sul, ilustra-se um trecho da ciclofaixa sobre calçada na Avenida Tupy (Figura 4). Neste trecho, observa-se a sinalização horizontal e vertical destacando o espaço exclusivo da bicicleta, bem como a demarcação da faixa. Há além da faixa para a calçada, espaço considerável para o tráfego dos pedestres, o que ajuda a evitar conflitos por espaço. Contudo, verificou-se em campo que os pedestres também caminham dentro do espaço delimitado para a bicicleta. Já na Figura 5 (extensão da Rua Tocantins), percebe-se que o espaço da calçada destinado ao pedestre é pequeno e não é possível mais do que duas pessoas transitarem lado a lado sem invadir o espaço da ciclofaixa.

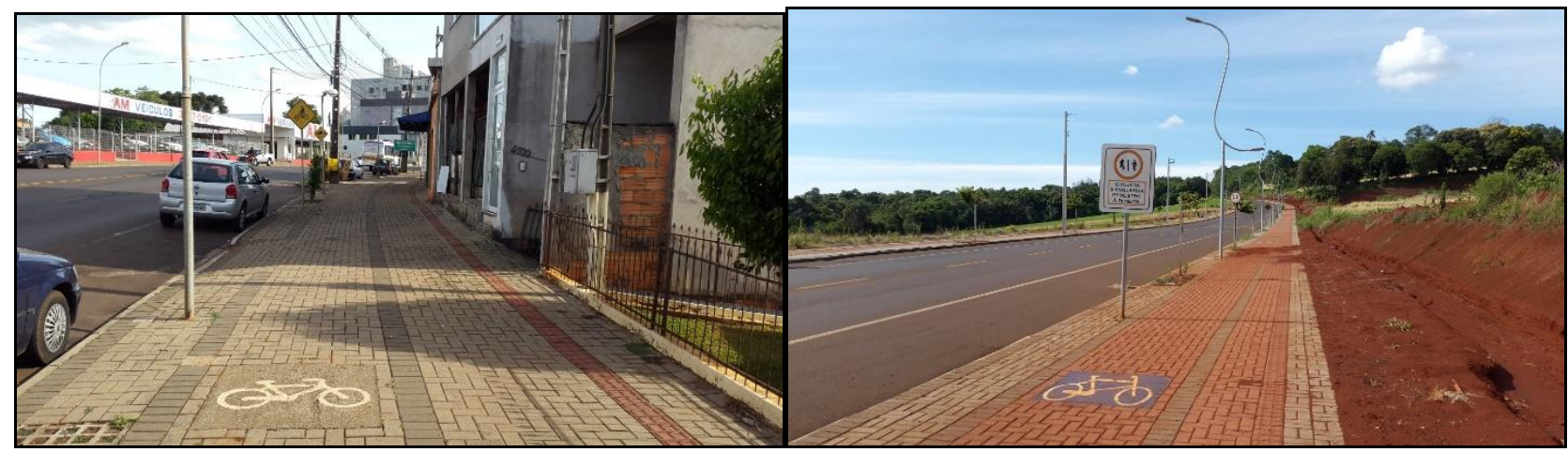

\section{Figura 4 (esquerda): Ciclofaixa sobre calçada na Avenida Tupy}

Figura 5 (direita): Ciclofaixa sobre calçada na extensão da Rua Tocantins (2016)

Tratando-se das ciclofaixas sobre calçada, na Rua Ivaí (Figura 6), foi onde percebeu se o caso mais crítico. Ainda, além do espaço para o pedestre ser mínimo na calçada fora da área delimitada como ciclofaixa, há interferências dentro da faixa como exemplo, um ponto de ônibus. Também é possível visualizar um pedestre caminhando dentro da ciclofaixa, o que é bastante comum no local.

Além das questões apresentadas nas imagens, outros problemas recorrentes observados na ciclofaixa sobre a calçada são as barreiras físicas temporárias, como tapumes de obras ou resíduos grandes deixados sobre a calçada, desníveis para acesso de garagem, presença constante de tráfego transversal de pedestres cruzando a ciclofaixa em áreas comerciais, bem como, dependendo da largura da calçada, descontinuidade repentina da ciclofaixa.

Como pode ser observado no mapa da figura 3 , a ciclofaixa sobre a calçada dá lugar à ciclofaixa na Avenida Tupy. Essa passagem é realizada de um lado da via para o outro sobre uma faixa elevada e segue até o trevo de entrada da cidade da zona sul. A Figura 7 apresenta a ciclofaixa, e como pode ser observado, é uma ciclofaixa demarcada atráves de pintura e sinalizações horizontais, bem como tachões para criar uma barreira física com a faixa dos carros. Esta ciclofaixa é ampla e possui demarcações como sendo uma ciclofaixa de dois sentidos. Dentre as vias com infraestrutura cicloviária, esta é a que melhor se adequa em termos de segurança e usabilidade na cidade.

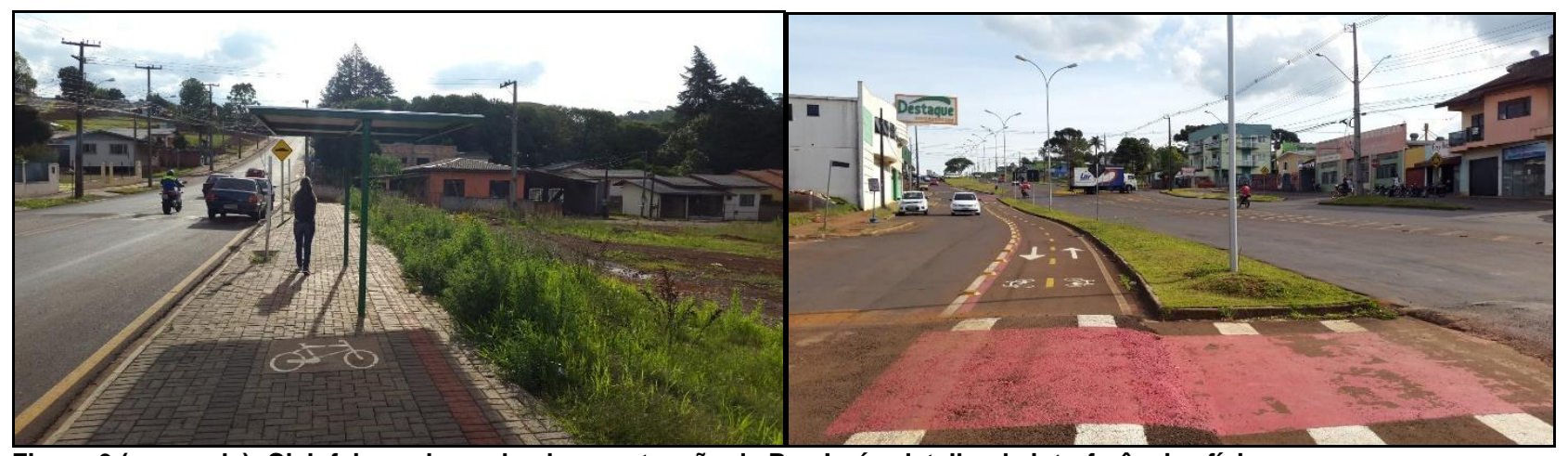

Figura 6 (esquerda): Ciclofaixa sobre calçada na extensão da Rua Ivaí - detalhe de interferências físicas Figura 7 (direita): Ciclofaixa na Avenida Tupy (2016)

Analisando as vias da zona norte, percebe-se que logo após o trevo da Avenida Tupy com a BR 158, existe uma pequena ciclofaixa em verde (Figura 8). Este design de ciclofaixa, tendo como separação do tráfego de 
veículos o estacionamento paralelo é apropriado para dar mais segurança ao ciclista. Contudo, é necessário ter atenção à abertura da porta do carro pelos passageiros. Um problema físico notado nesta ciclofaixa é a presença de bueiros dentro da limitação dela, o que é um risco grande de acidente para o ciclista, visto que na zona delimitada como faixa para bicicleta, não se espera encontrar obstáculos.

Contudo, os dois maiores pontos negativos encontrados nesta via é que esta ciclofaixa, diferentemente da existente na Avenida Tupy, segue somente o mesmo sentido da faixa dos veículos, logo, ela deveria existir em ambos os lados da rua, porém, só existe em um; o outro ponto, é em relação à continuidade desta ciclofaixa, tendo em vista que esta abrange somente duas quadras e não se conecta a nenhuma outra.

Outra via informada pela Prefeitura Municipal como possuindo infraestrutura cicloviária é a Via do Conhecimento - PR 493 (Figura 9). Este passeio pavimentado não é uma ciclovia exclusiva para ciclistas, tendo em vista que é o único acesso para pedestres até a Universidade Tecnológica Federal do Paraná (Figura 20). Contudo, em virtude do baixo tráfego de pedestres, é uma estrutura que acaba funcionando bem como ciclovia.

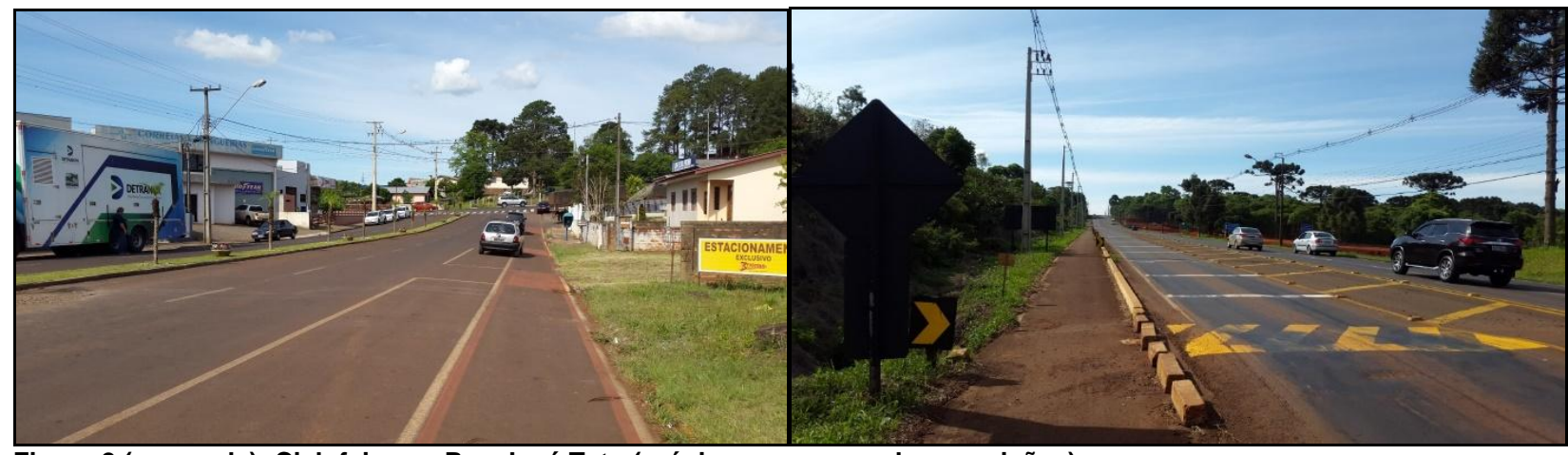

Figura 2 (esquerda): Ciclofaixa na Rua José Tato (próximo ao parque de exposições)

Figura 9 (direita): Ciclovia na Via do Conhecimento - sentido UTFPR

(2016)

O panorama atual da infraestrutura cicloviária em Pato Branco é, em resumo, ciclovias sem padronização e sem conectividade, o que representa que as implantações não têm sido pensadas como um sistema cicloviário, mas sim como adaptações pontuais ou pequenas intervenções em vias que passarão por reformas.

Outro indicador que o IMUS sugere analisar é a integração entre o modal cicloviário e o transporte público, contudo, não há nenhum tipo de integração entre estes modais e nem infraestrutura existente para tal. Segundo a PMPB, em nenhum ponto de ônibus há estacionamento para bicicletas, e em realidade, o único estacionamento para bicicleta em espaço público encontrado durante os levantamentos de campo foi na praça central do município. Além disso, tratando-se dos ônibus, não há nenhuma adaptação para facilitar o carregamento de bicicletas durante a viagem.

Portanto, a conclusão da análise descritiva conduzido pela ferramenta IMUS, é que há muito espaço para melhoria no sistema cicloviário da cidade de Pato Branco, tanto em padronização, formatação e adaptação destas vias, tendo em vista que em diversos locais foram encontradas muitas barreiras físicas dentro do espaço da ciclovia, quanto na criação de uma malha viária interconectada que permita ao ciclista trafegar com segurança por toda a cidade.

\subsection{Análise das vias através do Nível de Stress de Sorton e Walsh}

Como previamente apontado anteriormente, não foi possível obter a velocidade média das vias, logo, um dos itens desta ferramenta não foi passível de análise. Além disso, para alguns trechos também não foi possível a obtenção do volume de veículos, logo, a análise não foi viável neste aspecto também para estes trechos. Portanto, a média do Nível de Stress da via foi calculada como sendo a média das notas obtidas para cada análise realizada no trecho.

Para exemplificar como foi realizada a tabulação de dados desta etapa, segue Tabela 10 - alguns trechos no sentido norte. 


\begin{tabular}{|c|c|c|c|c|c|c|c|c|c|}
\hline Rua & Trecho & $\begin{array}{l}N^{\circ} \text { de } \\
\text { faixas }\end{array}$ & Início trecho & Fim trecho & $\begin{array}{c}\text { VHP } \\
\text { (V/F/HP) }\end{array}$ & $\begin{array}{c}\text { Nivel } \\
\text { de } \\
\text { Stress }\end{array}$ & $\begin{array}{l}\text { Largura } \\
\text { da Faixa } \\
\text { (m) }\end{array}$ & $\begin{array}{c}\text { Nivel } \\
\text { de } \\
\text { Stress } \\
\end{array}$ & $\begin{array}{c}\text { Nivel de } \\
\text { Stress } \\
\text { da via } \\
\end{array}$ \\
\hline Paraná S-N & N1 & 1 & Avenida Tupy & $\begin{array}{l}\text { Pedro Ramires } \\
\text { de Melo }\end{array}$ & & & 2,9 & 5 & 5 \\
\hline Avenida Brasil S-N & N1 & 1 & Avenida Tupy & Xavantes & 292 & 3 & 3,80 & 3 & 3 \\
\hline Avenida Brasil S-N & N2 & 1 & Xavantes & Xingu & 292 & 3 & 3,85 & 3 & 3 \\
\hline Avenida Brasil S-N & N3 & 1 & Xingu & $\begin{array}{l}\text { Pedro Ramires } \\
\text { de Melo }\end{array}$ & 292 & 3 & 3,95 & 3 & 3 \\
\hline Tamoio S-N & N2 & 2 & Xavantes & $\begin{array}{l}\text { Pedro Ramires } \\
\text { de Melo }\end{array}$ & 361 & 4 & 4,00 & 3 & 3,5 \\
\hline Tamoio S-N & N3 & 2 & $\begin{array}{c}\text { Pedro Ramires } \\
\text { de Melo }\end{array}$ & |biporã & 176 & 2 & 4,00 & 3 & 2,5 \\
\hline Guarani S-N & N1 & 1 & Avenida Tupy & lguaçu & & & 3,60 & 4 & 4 \\
\hline Guarani S-N & N2 & 2 & lguaçu & Tapir & 247 & 3 & 3,80 & 3 & 3 \\
\hline Guarani S-N & N3 & 2 & Tapir & Osvaldo Aranha & 230 & 3 & 3,95 & 3 & 3 \\
\hline Tapajós S-N & N1 & 2 & lguaçu & Ibiporã & & & 3,00 & 5 & 5 \\
\hline
\end{tabular}

Tabela 2: Nível de Stress - sentido Norte (2016)

Nestes trechos do sentido norte, o Nível de Stress variou de moderado (3) a muito alto (5), tendo apenas um caso com avaliado como baixo (2). Nos Níveis de Stress em função do volume, nenhum atingiu nota 5, o que pode indicar que as vias em que se estima menor volume, teriam Níveis de Stress menores do que os tabulados.

Ainda no sentido norte, analisando as vias classificadas com Nível de Stress Moderado, vê-se a Avenida Brasil, Rua Tamoio, Rua Guarani e Rua Tapajós como as mais propícias para o uso da bicicleta. Já a Avenida Tupy, aparece com um Nível de Stress alto em função da pequena largura das faixas.

Já nos trechos no sentido sul, percebe-se que as vias de mão-dupla tem Níveis de Stress semelhantes aos apresentados no sentido Norte, exceto a Avenida Tupy que reduz o Nível de Stress de uma média alta para uma média moderada. Contudo, no sentido Sul são apresentadas duas novas vias com sentido único, a Rua Caramuru e Rua Goianases, sendo a primeira avaliada em média com Nível de Stress moderado. Já a Goianases apresenta maior variação entre seus trechos, indo de muito baixo a muito alto. Esta variação se deve à mudança de duas faixas estreitas para uma faixa mais larga na quadra.

Para os trechos no sentido leste, verificou-se que das dez ruas estudadas, seis tem em seus trechos Nível de Stress moderado, uma apresenta Nível de Stress alto e duas muito alto. Contudo, somente quatro vias possuem dados relativos ao volume de tráfego, sendo que estes variam, em maioria, entre Nível de Stress moderado e alto. Percebe-se, também, que a avaliação das ruas Jaciretã e Osvaldo Aranha está somente em função da largura da faixa, contudo, apesar da faixa estreita, estima-se que são ruas com velocidades médias baixas e volumes menores fora do horário de pico, o que se avaliado em conjunto, diminuiria o Nível de Stress da via.

Para os trechos no sentido oeste, pode-se perceber que as vias foram as que menos dados foram obtidos tendo o volume somente de três dos vinte e dois trechos estudados. Tratando-se ainda sobre os volumes, verifica-se que somente as vias de mão única são as que possuem estes dados, sendo as vias de mão dupla as que ficaram sem informações de volume. Logo, como a largura das faixas é muito semelhante para as vias de mão dupla, os Nível de Stress são idênticos. Em relação às ruas com novos dados, Tapir e Ibiporã, ambas são classificadas com Nível de Stress moderado.

Ainda uma informação interessante que pode ser destacado nos trechos no sentido oeste é como é significativa para esta ferramenta a largura da via, pois a Rua Tapir apresenta o maior volume de tráfego no horário de pico (435 veículos por faixa/hora) entre todas as vias estudadas, contudo, o Nível de Stress desta via é 3,5. Já, a Rua Itabira, em parte de seu trecho, possui a metade do volume (213 veículos/hora), mas Nível de Stress 4, em virtude da faixa mais estreita (2,75m contra 3,75m da Rua Tapir). 
Em relação à análise em virtude da velocidade média, tem-se que o limite de velocidade de todas estas vias é $40 \mathrm{~km} / \mathrm{h}$, e mesmo que em algumas vias se perceba que este limite não seja respeitado, dificilmente atinge-se mais que $60 \mathrm{~km} / \mathrm{h}$ nas vias centrais. Logo, isto indica que uma análise de velocidade média apresentaria Níveis de Stress menores para algumas vias, então, este indicador iria baixar o valor final.

De modo geral, observou-se que tanto as vias do eixo norte-sul, quanto as do eixo leste-oeste possuem Nível de Stress variando entre moderado, alto e muito alto. Porém, levando em consideração a observação sobre a estimativa da velocidade média, todos os Nível de Stress reduziriam pelo menos para o nível alto e flutuariam entre baixo, moderado e alto. Desta forma, segundo a avaliação da ferramenta todas as vias precisariam de alguma alteração ou ajuste compensatório para poder abrigar todas as faixas etárias de ciclista, sendo as vias com níveis baixo e moderado mais propícias para ciclistas jovens e casuais, e as vias com nível alto de stress indicadas somente para ciclistas mais experientes.

\subsection{Análise das vias através do Índice de Condição das Vias de Epperson-Davis}

Da mesma maneira que na análise do Nível de Stress, não há informações de volume de tráfego para todas as vias. Contudo, através de simulações, percebeu-se que para esta ferramenta a variável VMD não influencia de maneira significativa o resultado. Explica-se: se o VMD por faixa for 400, por exemplo, há variação de somente 0,13 no valor do ICV, enquanto que para o Fator de Pavimento, a observação de bueiros na via significa um aumento de 0,5 no resultado do ICV. Logo, considerou-se que apesar de algumas vias possuírem VMD e outras não, a análise global não seria prejudicada.

Para exemplificar (Tabela 11) apresentam-se como os dados foram tratados para o Índice de Condição das Vias - alguns trechos sentido norte.

\begin{tabular}{|c|c|c|c|c|c|c|c|c|c|c|}
\hline Rua & Trecho & Início trecho & Fim trecho & VMD & $f$ & V & $L$ & $F P$ & $F L$ & ICV \\
\hline Paraná S-N & N1 & Avenida Tupy & $\begin{array}{l}\text { Pedro Ramires } \\
\text { de Melo }\end{array}$ & & 1 & 40 & 2,9 & 0,5 & 0,75 & 3,92 \\
\hline Av. Brasil S-N & N1 & Avenida Tupy & Xavantes & 248 & 1 & 40 & 3,80 & 0 & 0,5 & 2,03 \\
\hline Av. Brasil S-N & N2 & Xavantes & Xingu & 248 & 1 & 40 & 3,85 & 0 & 0,5 & 1,96 \\
\hline Av. Brasil S-N & N3 & Xingu & $\begin{array}{l}\text { Pedro Ramires } \\
\text { de Melo }\end{array}$ & 248 & 1 & 40 & 3,95 & 0 & 0,95 & 2,27 \\
\hline Tamoio S-N & N1 & Xavantes & $\begin{array}{l}\text { Pedro Ramires } \\
\text { de Melo }\end{array}$ & 606 & 2 & 40 & 4,00 & 0,5 & 0,75 & 2,52 \\
\hline Tamoio S-N & N2 & $\begin{array}{l}\text { Pedro Ramires } \\
\text { de Melo }\end{array}$ & |biporã & 434 & 2 & 40 & 4,00 & 0,5 & 0,95 & 2,69 \\
\hline Guarani S-N & N1 & Avenida Tupy & lguaçu & & 1 & 40 & 3,60 & 0 & 0 & 1,72 \\
\hline Guarani S-N & N2 & Iguaçu & Tapir & 430 & 2 & 40 & 3,80 & 0,5 & 1,7 & 3,72 \\
\hline Guarani S-N & N3 & Tapir & Osvaldo Aranha & 389 & 2 & 40 & 3,95 & 0,25 & 1,5 & 3,05 \\
\hline Tapajós S-N & N1 & Iguaçu & |biporã & & 2 & 40 & 3,00 & 0,5 & 1,45 & 4,49 \\
\hline
\end{tabular}

Tabela 11: Índice de Condição das Vias - sentido norte

(2016)

Analisando os resultados coletados para os trechos no sentido norte, verifica-se que o índice gerado para a maioria das vias está concentrado no intervalo entre 2 e 4. Levando em conta o critério de classificação da ferramenta, dos 27 trechos, 16 são classificados como Excelente, 10 trechos como Bom e um como Regular. Em relação aos trechos classificados como Excelente, destacam-se as seguintes vias: Avenida Brasil, Rua Aimoré, parte da Rua Tapajós e da Rua Tamoio. Quanto aos trechos classificados como Bom, pode-se destacar a Rua Tocantins, Avenida Tupy, Rua Guarani, Rua Paraná e Rua Itapuã.

Já para os trechos no sentido sul, em proporção semelhante aos trechos no sentido Norte, a maior parte dos trechos (29 de 33) concentram-se entre os índices 2 e 4, tendo quatro trechos com índice inferior a 2. Em relação à classificação dos trechos, vinte e quatro são classificados como Excelente e nove como Bom. As vias que se destacam como Excelente nesta classificação são as ruas Aimoré, Goianases, Tapajós, Caramuru, Avenida Brasil e parte da Avenida Tupy. Já em relação às vias classificadas como Boas, apontam-se as ruas Paraná, Tocantins, Itapuã e parte da Avenida Tupy. 
Para os trechos no sentido leste, dos vinte e um trechos levantados, oito são classificados como Excelente, onze como Bom e dois como Regular. Percebeu-se que a maioria dos trechos (18) estão dentro do intervalo entre os índices 2 e 4 . As vias que podem ser classificadas como Excelente, portanto, são as ruas Iguaçu, Dr. Silvio Vidal, Pedro Ramires de Melo e Ibiporã. Já as vias que são classificadas como Boas são: Rua Mato Grosso, Rua Xingu, Rua Ararigboia, Rua Jaciretã e a maior parte da Rua Itabira. Em relação aos trechos classificados como Regular, fazem parte das ruas Osvaldo Aranha e Itabira.

Seguindo o mesmo padrão dos resultados anteriores, os trechos no sentido oeste são muito semelhantes ao primeiro exposto. Destes vinte e dois trechos, vinte estão dentro do intervalo entre índices 2 a 4 . Contudo, no sentido Oeste, há quatro trechos a mais classificados como Excelente do que no sentido Leste, totalizando doze. Nove são classificados como Bom e um como Regular. A via que se encaixa parcialmente como Regular no trecho é a Rua Osvaldo Aranha. Como Excelente, destacam-se cinco ruas: Itacolomi, Dr. Silvio Vidal, Iguaçu, Ibiporã e Tapir. E classificadas como Boas, ficam cinco vias, as ruas Mato Grosso, Xavantes, Pedro Ramires de Melo, Jaciretã e Itabira.

Em uma análise geral dos resultados do Índice de Condição das Vias, verifica-se que do total de 103 trechos estudados, 62 são classificados como Excelente e 37 como Bom, ou seja, 96\% dos trechos da amostra são considerados Bom ou Excelente para o tráfego de bicicletas.

Acredita-se que este resultado tão significativo tenha se dado, em parte, em função da ótima condição do pavimento, que em poucos casos apresentou sinais de deterioração. Portanto, os pontos de Fator de Pavimento foram, em sua maioria, gerados pela presença de bueiros em locais que poderiam gerar risco ao ciclista. Além disso, como já explicado anteriormente, o fator volume de tráfego tem influência muito baixa nos resultados, apesar de ser um fator mais substancial e menos subjetivo do que os Fatores de Pavimento e Localização.

Outra questão importante percebida durante a análise, é a limitação da ferramenta para a avaliação de diferentes graus de declividade das vias, o que faz com que um trecho muito íngreme não seja classificado como Ruim, ou até mesmo Regular, se a largura da faixa for grande.

Buscando entender esta questão, pesquisou-se sobre a cidade em que a ferramenta foi baseada (Hollywood, Flórida, EUA) e o que se verificou é que esta cidade é extremamente plana. Então, compreendeu-se que na equação gerada por Epperson (1994) para esta ferramenta, baseada na cidade local, a largura das faixas era, de fato, muito mais influente no resultado do que a declividade das vias, visto que são raras as ruas com declive. Outro aspecto percebido é que a influência do volume de tráfego possa parecer baixa em virtude do possível baixo volume de tráfego de Pato Branco, caso fosse comparado com o da cidade de origem da ferramenta.

Portanto, apesar da importante análise possibilitada por esta ferramenta, tendo em vista que toda a coleta de dados e visitas de campo tiveram seu olhar baseado nela, considera-se que os resultados obtidos através dela precisam ser cuidadosamente interpretados trecho a trecho, para que não sejam cometidos equívocos, principalmente no que tange ao relevo local. Contudo, destaca-se para que os trechos sem declividade acentuada, os resultados são compatíveis com a observação em campo.

\subsection{Análise dos Resultados}

A apresentação da avaliação final dos resultados também se deu por tabulação dos dados em tabela, de forma semelhante ao já realizado no Nível de Stress e ICV, com o adendo do mapa síntese, ao final. Nas tabelas finais, foram separadas por sentido dos trechos e apresentadas as vias, trechos, número de faixas, ruas que delimitam o início e fim do trecho, resultado do Nível de Stress e ICV, e por fim, a classificação da via através da cor.

A Tabela 12, apresenta parte da tabulação final - alguns trechos sentido norte. 


\begin{tabular}{c|ccccccc|l|}
\hline \multicolumn{1}{c}{ Rua } & Trecho & $\begin{array}{c}\text { No de } \\
\text { faixas }\end{array}$ & Início trecho & Fim trecho & $\begin{array}{c}\text { Nivel } \\
\text { de } \\
\text { Stress }\end{array}$ & ICV & \multicolumn{2}{c}{$\begin{array}{c}\text { Classificação } \\
\text { da via }\end{array}$} \\
\hline Avenida Tupy S-N & N5 & 2 & Tapir & Osvaldo Aranha & 4,5 & 3,17 & \\
\hline Tocantins S-N & N1 & 1 & Mato Grosso & Itacolomi & 3 & 2,38 & \\
\hline Tocantins S-N & N2 & 2 & Itacolomi & Ararigbóia & 5 & 3,15 & \\
\hline Tocantins S-N & N3 & 2 & Ararigbóia & Jaciretă & 5 & 2,92 & \\
\hline Tocantins S-N & N4 & 2 & Jaciretã & Itabira & 5 & 3,79 & \\
\hline Aimoré S-N & S1 & 1 & Itacolomi & Ararigbóia & 4 & 2,97 & \\
\hline Aimoré S-N & S2 & 1 & Ararigbóia & Dr. Silvio Vidal & 4 & 2,47 & \\
\hline Aimoré S-N & S3 & 1 & Dr. Silvio Vidal & Ibiporã & 4 & 2,47 & \\
\hline Aimoré S-N & S4 & 1 & Ibiporã & Jaciretã & 4 & 2,58 & \\
\hline Aimoré S-N & S5 & 1 & Jaciretă & Itabira & 4 & 2,58 & \\
\hline
\end{tabular}

Tabela 12: Classificação da via - sentido norte

(2016)

Verificou-se que nos trechos do sentido norte, dez trechos foram classificados como Excelente, sete como Bom, seis Regular e quatro como Ruim. Comparando os resultados das ferramentas utilizadas com a classificação atual, percebe-se que a maioria dos trechos verdes (Excelente ou Bom) possuem ICV abaixo de 3 e Níveis de Stress em 3. Há poucas exceções e que, em geral possuem índices maiores, pela largura pequena da faixa. Para os trechos amarelos (Regular), percebe-se ICV em maioria maior que 3 e Níveis de Stress maiores ou igual a 4, exceto um trecho. E, para os trechos vermelhos (Ruim), há uma variação maior do ICV, entre valores menores do que 3 e maiores do que 3 , o que justifica a questão exposta sobre a impossibilidade da ferramenta aumentar o valor do índice em função da alta declividade, mas os Níveis de Stress permanecem altos entre 4 e 5 . Como destaque para opção com maior potencial para rotas cicláveis no sentido norte, apresentam-se a Avenida Brasil, Rua Tamoio, Rua Guarani e partes da Avenida Tupy e Rua Tocantins.

Nos trechos do sentido sul foram avaliados quinze trechos Excelente, seis trechos Bom, oito Regular e quatro Ruim. Todos os trechos verdes possuem ICV abaixo de 3 ou ligeiramente acima de 3 (somente três casos). Em relação aos Níveis de Stress para os trechos Excelente ou Bom, a maioria está classificado como menor que 4, somente com também três exceções. Para os trechos amarelos, percebe-se Níveis de Stress mais altos (4 ou 5) e valores de ICV variantes entre 2 e 4 . Por fim, para os trechos vermelhos, também em maioria os Níveis de Stress estão em 4 ou 5, e o ICV variando entre 2 e 4 . Uma exceção é a Rua Goianases que apresenta ICV 2,38 e Nível de Stress 3. Contudo, estes valores foram puxados para baixo pela largura de $3,85 \mathrm{~m}$ da faixa neste trecho, mas a grande declividade não consegue ser apresentada dentro das ferramentas.

Destacam-se no sentido sul como boas opções para rotas cicloviárias as seguintes vias: Avenida Brasil, Rua Caramuru, Rua Tapajós e Avenida Tupy. Ainda como opções, mas que dependem de alguns ajustes maiores na via, a Rua Tocantins, Rua Goianases e Rua Aimoré possuem trechos propícios para o deslocamento com bicicleta.

No sentido leste, seis trechos foram avaliados como Excelente, oito trechos como Bom, quatro como Regular e três como Ruim. Percebe-se inicialmente, uma diferença nos trechos Bom neste eixo, em relação ao eixo Norte-Sul, pois a maioria dos trechos classificados como Bom possuem Nível de Stress 5 e ICV maior do que 3. Contudo, isso se deve ao fato da largura das faixas destas ruas serem pequenas, contudo, em virtude da baixa velocidade dos veículos observada em campo, percebe-se grande potencial para tráfego compartilhado, em virtude do relevo plano destas vias.

Os trechos classificados como Excelente, mantém, em sua maioria, o padrão observado nas tabelas anteriores: ICV abaixo de 3 ou ligeiramente acima e Nível de Stress moderado (3). Já para os trechos Regular e Ruim, percebe-se variação grande tanto no ICV quanto no Nível de Stress. Essa variação, novamente, se dá pela falha da ferramenta em ou aumentar muito o ICV e Stress em função da largura pequena da faixa ou diminuir o ICV e Stress em função do oposto, uma faixa mais larga. Exemplifica-se com o trecho L1 da rua Osvaldo Aranha, que possui uma faixa estreita de 3,00m, mas um declive não tão acentuado, se comparada com a inclinação da rua Dr. Silvio Vidal trecho L1. Contudo, o trecho L1 da rua 
Dr. Silvio Vidal possui faixa com $3,80 \mathrm{~m}$ de largura. Destacam-se, então, como rotas cicloviárias preferenciais no sentido Leste as ruas Mato Grosso, Xingu, Pedro Ramires de Melo, Iguaçu, Jaciretã e partes da Itabira e Osvaldo Aranha.

No sentido oeste, dois terços dos trechos foram avaliados como Bom ou Excelente, quanto aos demais, seis foram avaliados como Regular e dois como Ruim. A avaliação comparativa entre a classificação pelas cores com o ICV e Nível de Stress é semelhante ao sentido Leste, tendo os trechos Excelente com baixos valores de ICV (abaixo de 3) e Níveis de Stress (maioria 3). Em relação aos trechos Bom, também ocorreu a grande variação entre valores baixos e altos de ICV e Níveis de Stress. Conforme colocado anteriormente, esta variação se explica pela consideração de ruas com faixa estreita, porém baixa velocidade de tráfego e relevo plano, com grande potencial para as rotas.

Curiosamente, os dois trechos vermelhos (Ruim) obtiveram classificação Excelente no ICV e Nível de Stress Moderado. Contudo, isto também se explica pelo fato de serem trechos muito íngremes, contudo, com faixas largas. Já os trechos avaliados como Regular, possuem declividade média e a largura das vias variável. Como rotas cicloviárias mais atraentes no sentido Oeste, destacam-se as ruas Mato Grosso, Xavantes, trechos da Itacolomi, Iguaçu, Jaciretã, Tapir e Osvaldo Aranha.

Com o objetivo de facilitar a compreensão espacial dos dados apresentados demarcou-se, sobre a imagem da área de estudo, a cor referente à avaliação final de cada trecho (Figura 10).

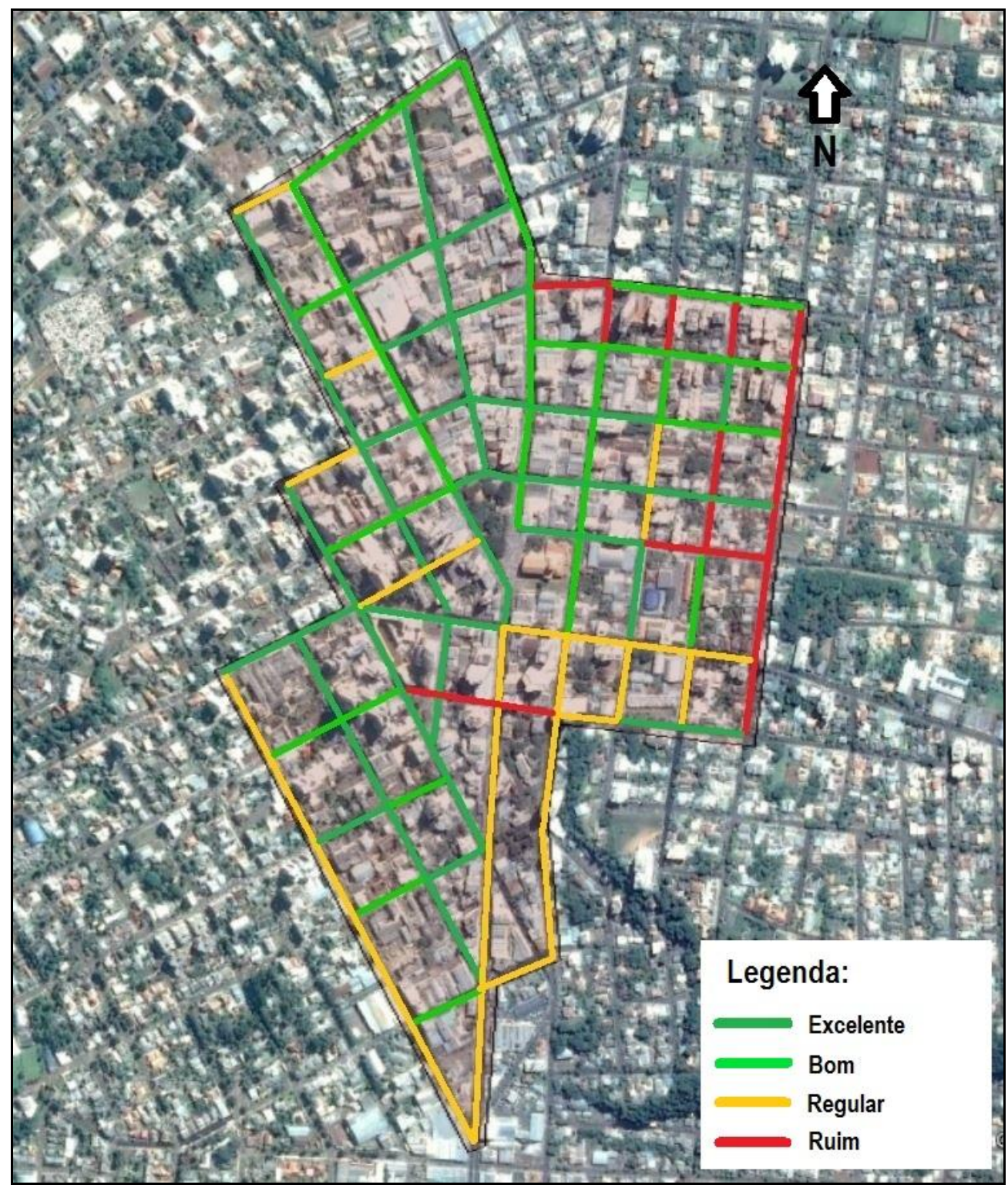

Figura 10: Mapa ilustrativo com os trechos avaliados

(Autor, Adaptado de Google Earth, 2016). 
Analisando a Figura 10, percebe-se que os trechos avaliados como Bom ou Excelente se localizam próximo à praça Getúlio Vargas e no norte da área de estudo, bem como no sudoeste, em região próxima aos bairros Baixada e Santa Terezinha, onde o relevo da cidade é mais plano. Os trechos Ruim se localizam principalmente na região Leste da área de estudo em função do relevo acidentado. Por fim, os trechos Regular, apesar de espalhados pela área de estudo, concentram-se na região sul, nas ruas Paraná, Tocantins e Avenida Tupy. No Gráfico 1, pode-se conferir um resumo das avaliações.

Do total de 103 trechos avaliados neste estudo, 38 deles foram avaliados como Excelente (37\%), 28 avaliados como Bom (27\%) e 24 como Regular (23\%). Somente 13 trechos (13\%) obtiveram avaliação Ruim em relação à sua capacidade de comportar bem o uso da bicicleta.

\section{CONSIDERAÇÕES FINAIS}

O conceito de sustentabilidade, conforme destacado por Litman (2003), deve ter impacto significativo no planejamento da mobilidade urbana, tendo em vista que o setor dos transportes tende a consumir intensamente recursos naturais não renováveis, gerar inúmeros custos externos e, frequentemente, distribuir estes impactos na sociedade de maneira desigual.

Acredita-se que o principal a ser modificado é o de que as ruas são feitas para os carros. A finalidade de uma rua existir é o tráfego de pessoas, e essas pessoas, antes de condutores de veículos, são pedestres. Portanto, as ruas precisam ser pensadas de forma mais humanizada, onde comportem de forma segura e agradável, todos os modais que por ali sejam úteis transitar.

Buscando explorar a hipótese popular de que "Pato Branco não é uma cidade para bicicletas", estudou-se a realidade do sistema cicloviário da cidade, e se comprovou que, neste momento, Pato Branco não é uma cidade para bicicletas, mas que há a possibilidade de uma rota cicloviária ser inserida na região central, possibilitando as pessoas que residem nesta região trocarem seu modal de transporte e realizar viagens locais com a bicicleta. Porém, ressalta-se que esta área é pequena e limitada, mas o potencial de expansão das rotas cicloviárias para os bairros e zonas industriais é grande.

Espera-se que seja incentivado à criação de políticas públicas no município e novas pesquisas que incentivem o uso da bicicleta enquanto modal regular de transporte, visto que, apesar da cidade ainda não possuir uma infraestrutura cicloviária, Pato Branco possui sim, potencial para ser uma cidade de bicicletas.

\section{BIBLIOGRAFIA}

BRASIL. Lei n¹2.597, de 21 de março de 2012. Brasília - DF. Março de 2012.

BRASIL. Desenvolvimento de Infra-Estrutura de Transportes no Brasil: Perspectivas e Desafios. Tribunal de Contas da União. Brasília. 2007.

CONTERNO, R. C. (2013) O transporte público coletivo a partir do conceito de mobilidade urbana sustentável: um estudo de caso na cidade de Pato Branco/PR. Dissertação (Mestrado). Programa de Pós-Graduação em Desenvolvimento Regional. Universidade Tecnológica Federal do Paraná, Pato Branco. Disponível em:

<http://repositorio.utfpr.edu.br/jspui/bitstream/1/700/1/PB_PPGDR_M_Conterno, Rayana Carolina_2013.pdf.pdf> (Consulta: 11/04/2016).

COSTA, M. S. (2008). IMUS Índice de Mobilidade Urbana Sustentável: Guia de Indicadores. Tese (Doutorado). Escola de Engenharia de São Carlos, Universidade de São Paulo, São Carlos, 2008.

EPPERSON, T. B. (1994) Evaluating suitability of Roadways for Bicycle Use: Toward a Cycling Level of Service Standard. Transportation Research Record.

GOOGLE EARTH. (2016) Software. Disponível para download em: <https://www.google.com/earth/>. (Consulta: 05/05/2016).

INSTITUTO BRASILEIRO DE GEOGRAFIA E ESTATíSTICA. (2016). Dados Censo 2010. Disponível em: $<$ http://cidades.ibge.gov.br/xtras/perfil.php?codmun=411850>. (Consulta: 07/05/2016).

LITMAN, T. (2003) Reinventing Transportation: Exploring the Paradigm Shift Needed to Reconcile Transportation and Sustainability Objectives. Victoria. Disponível em <http://www.vtpi.org/reinvent.pdf>. (Consulta: 12/04/2016). 
LOGITRANS - Logística Engenharia e Transportes. (2015) Estudo Técnico e Projeto Básico do Transporte Coletivo Urbano de Pato Branco. 2015. Disponível em: <http://patobranco.pr.gov.br/licitacoes/>. (Consulta: 08/10/2015).

PATO BRANCO. (2006) Instituto De Pesquisa e Planejamento Urbano de Pato Branco. Anexo IX - Mapa de Estruturação e Hierarquia da Malha Viária. Disponível em: http://www.patobranco.pr.gov.br/planejamento-urbano/. (Consulta: 08/10/2015).

ROLNIK, R. (2004). O que é a cidade. 3. ed. São Paulo: Brasiliense.

RUBIM, B., LEITÃO, S. (2013). O plano de mobilidade urbana e o futuro das cidades. Curso de Direito, Universidade de São Paulo. São Paulo.

SORTON, A., WALSH, T. (1994). Bicycle Stress Level as a Tool to Evaluate Urban and Suburban Bicycle Compatibility.1994. 8 f. Artigo. Washington.

TABALIPA, N. L., FIORI, A. P. (2012). Caracterização dos solos da bacia do Rio Ligeiro (PR) na estabilidade de taludes. 2012. 16f. Revista Brasileira de Geociências.v. 42, n. 1 (2012). Disponível em: <http://igc.usp.br/igcJournal/index.php/rbg/article/view/7871/0>. (Consulta: 22/05/2016). 